Extent of ILD in $\mathbf{5 2}$ patients with JMCTD

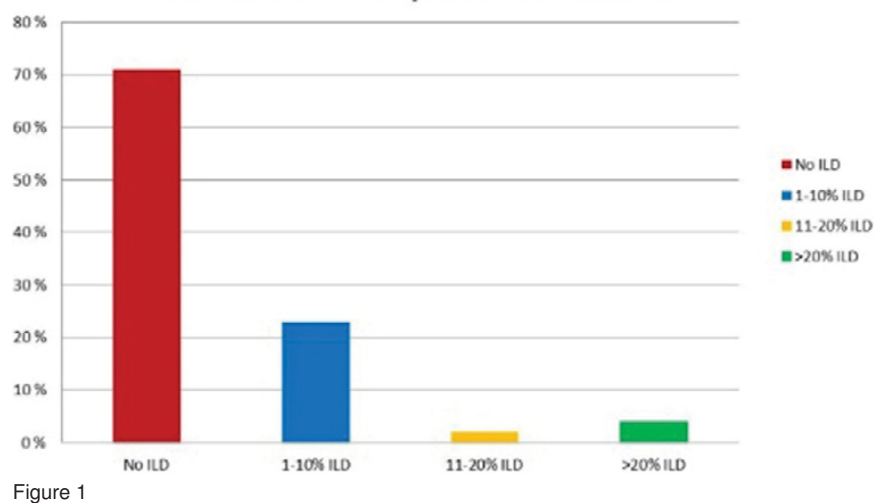

DOI: 10.1136/annrheumdis-2017-eular.1366

\section{OP0014 CONVENTIONAL RADIOGRAPHY IN JUVENILE IDIOPATHIC ARTHRITIS: JOINED RECOMMENDATIONS FROM THE FRENCH SOCIETIES FOR RHEUMATOLOGY, RADIOLOGY AND PEDIATRIC RHEUMATOLOGY}

P. Marteau ${ }^{1}$, C. Adamsbaum ${ }^{2}$, L. Rossi-Semerano ${ }^{3}$, M. De Bandt ${ }^{4}$, I. Lemelle ${ }^{5}$, J. Wipff ${ }^{6}$, C. Deslandre 6,7, T.A. Tran $^{8}$, A. Lohse ${ }^{9}$, E. Solau-Gervais ${ }^{10}$

C. Sordet ${ }^{11}$, P. Pillet ${ }^{12}$, B. Bader-Meunier ${ }^{7}$, C. Gaujoux-Viala ${ }^{13}$, S. Breton ${ }^{14}$, V. Devauchelle-Pensec ${ }^{1,15,16} .{ }^{1}$ Rheumatology, CHU Brest, BREST; ${ }^{2}$ Pediatric Radiology, Bicêtre Hospital, Paris; ${ }^{3}$ Pediatric Rheumatology, Bicêtre Hospital, le Kremlin-Bicêtre; ${ }^{4}$ Rheumatology, Pierre Zobda Quitman University Hospital, Fort de France, ${ }^{5}$ Pediatric Rheumatology, Nancy University Hospital, Nancy;

${ }^{6}$ Rheumatology A, Cochin University Hospital; ${ }^{7}$ Pediatric Rheumatology, Necker Hospital, Paris; ${ }^{8}$ Pediatrics, Nîmes University Hospital, Nîmes; ${ }^{9}$ Rheumatology, Nord Franche Comté Hospital, Belfort; ${ }^{10}$ Rheumatology, Poitiers University Hospital, Poitiers; ${ }^{11}$ Rheumatology, Hautepierre Hospital, Strasbourg;

${ }^{12}$ Pediatrics, Pellegrin-enfants Hospital, Bordeaux; ${ }^{13}$ Rheumatology, Carémeau University Hospital, Nîmes: ${ }^{14}$ Pediatric Radiology, Necker Hospital, Paris;

${ }^{15}$ Pediatrics, CHU Brest: ${ }^{16}$ UMR 1227, Inserm, BREST, France

Background: Juvenile idiopathic arthritis (JIA) may lead to structural damage. Yet radiographic assessment is seldom considered in studies.

Objectives: To provide pragmatic quidelines concerning conventional radiography $(C R)$ in each subtype of JIA (exclusion of systemic JIA).

Methods: A multidisciplinary task force of 15 French experts (rheumatologists, pediatricians, radiologists) plus one patient's representative, was convened. Following the GRADE ${ }^{1}$ method, they formulated a series of research questions concerning $\mathrm{CR}$ assessment, at diagnosis and follow-up of each subtype of JIA. Systemic JIA was ruled out. A systematic literature review was conducted, considering articles in which structural damage was detailed (erosion, joint space narrowing, bone deformities). A series of recommendations was elaborated, following evidence-based data, and expert opinion. It underwent an evaluation from an independant committee (including patient's representative), and a final round of Delphi-voting process from the whole expert group.

Results: Of 646 publications identified, 73 original articles were included. The task force produced 4 principles and 31 recommendations. Level of evidence ranked from $B$ to $D$, level of agreement was high. The experts insisted on weighing indication of $\mathrm{CR}$ considering structural risk. The importance of assessing structural progression, the need for constant attention to radioprotection were asserted. Systematic CR of hands and feet are thus recommended in polyarthritis JIA rheumatoid factor positive, and in polyarticular JIA with pejorative prognostic factors. Systematic CR are not recommended in oligoarticular JIA. CR is not the prime imaging technique of the axial skeleton.

Conclusions: These are the first pragmatic recommendations upon CR in JIA. They mostly rely on experts' opinion, due to lack of evidence-based data. CR is still relevant in many situations in JIA, but should not be overlooked, while non-irradiating imagine techniques are developing.

\section{References:}

[1] Brożek JL, Akl EA, Compalati E, Kreis J, Terracciano L, Fiocchi A, et al. Grading quality of evidence and strength of recommendations in clinical practice guidelines part 3 of 3 . The GRADE approach to developing recommendations. Allergy. 2011 May;66(5):588-95.

Acknowledgements: Dr Bouchra Amine, Pr Nathalie Boutry, Pr Rolando Cimaz, Pr Bernard Combe, Dr Véronique Despert, M William Fahy and Mrs Céline Obert (association KOURIR), Dr Laurence Goumy, Pr Michael Hofer, Dr Laëtitia Houx, Dr Sylvie Jean, Dr Valérie Merzoug, Pr Michel Panuel, Pr Samira Rostom, Pr Jean Sibilia; the French Society for Rheumatology, the French Society for Radiology, The French Society for Pediatric and antenatal Imaging.

Disclosure of Interest: None declared

DOI: 10.1136/annrheumdis-2017-eular 3862
WEDNESDAY, 14 JUNE 2017

Still breaking news on TNF inhibitors in rheumatoid
arthritis

OP0015 INDUCTION OF REMISSION AND MAINTENANCE IN EARLY, AGGRESSIVE RHEUMATOID ARTHRITIS USING ADALIMUMAB IN COMBINATION WITH METHOTREXATE WITH OR WITHOUT SHORT-TERM HIGH-DOSE GLUCOCORTICOIDS: RESULTS OF A PHASE IV MULTICENTER, RANDOMIZED, DOUBLE BLIND STUDY (CLINTRIAL.GOV: NCT00480272)

R. Caporali ${ }^{1}$, C. Montecucco ${ }^{1}$, E. Bartoloni Bocci ${ }^{2}$, B. Vitolo ${ }^{1}$, E. Prisco ${ }^{1}$, C. Klersy ${ }^{3}$, R. Giacomelli ${ }^{4}$, G. Triolo ${ }^{5}$, M. Cutolo ${ }^{6}$, A. Marchesoni ${ }^{7}$, E. Gremese ${ }^{8}$, C. Iannuccelli ${ }^{9}$, R. Tirri ${ }^{10}$, W. Grassi ${ }^{11}$, G. Lopalco ${ }^{12}$ M. Galeazzi ${ }^{13}$, M. Matucci Cerinic ${ }^{14}$, L. Punzi ${ }^{15}$, G. Ferraccioli ${ }^{8} .{ }^{1}$ IRCCS San Matteo, Pavia; ${ }^{2}$ University of Perugia; ${ }^{3}$ Biometry Unit, IRCCS San Matteo, Pavia;

${ }^{4}$ University of L'Aquila, L'Aquila: ${ }^{5}$ University of Palermo, Palermo; ${ }^{6}$ University of Genoa, Genoa; ${ }^{7}$ ASST G Pini, Milano; ${ }^{8}$ Policlinico Gemelli, Roma; ${ }^{9}$ University la Sapienza, Rome; ${ }^{10}$ Seconda Università, Napoli; ${ }^{11}$ Università delle Marche,

Ancona; ${ }^{12}$ Azienda Policlinico, Bari; ${ }^{13}$ Azienda Ospedaliera Universitaria, Siena: ${ }^{14}$ Azienda Ospedaliera Universitaria, Firenze; ${ }^{15}$ Azienda Ospedaliera, Padova, Italy

Background: Remission is the current aim of early RA treatment. In patients with early, aggressive RA, combination with adalimumab (ADA) plus methotrexate (MTX) was superior to either MTX or ADA alone in obtaining clinical remission. Moreover, it has been demonstrated that a short-term aggressive treatment with high-dose glucocorticoids (GC) plus conventional DMARDs lead to long-term (up to 5 years) benefits.

Objectives: To compare the proportion of patients who achieve remission at 12 months, between two groups of subjects treated with ADA + MTX + high dose GC (intensive) and ADA + MTX + placebo (standard), and to evaluate the proportion of those maintaining remission at 24 months, after discontinuation of GC at 6 and ADA at 12 months.

Methods: The main inclusion criteria were: active RA, disease duration $\leq 1$ year, GC and MTX-naïvity, at least one predictor of aggressive disease. All subjects received ADA for 12 months and MTX (20 mg/w) to the end of month 24 . Subjects were randomized to receive prednisone (orally, $50 \mathrm{mg} / \mathrm{d}$, progressively tapered to $6.25 \mathrm{mg}$ and stopped at month 6) or placebo. Response was evaluated using DAS28, CDAI, SDAI and ACR response criteria. The difference in rate and $95 \%$ $\mathrm{Cl}$ will be computed with a binomial regression model and identity link, while clustering on center. An intention-to-treat analysis was performed.

Results: 118 patients were assigned to standard and 115 patients to intensive group. Remission (DAS28 $<2.6, \mathrm{SDAl} \leq 3.3, \mathrm{CDAl}<2.8$ ) at 1 year in standard vs intensive group were: $56.25 \%$ vs $45.28 \%(\mathrm{RD}=-11 \%, 95 \% \mathrm{Cl}-23$ to, $\mathrm{p}=0.07)$, $30.36 \%$ vs $21.69 \%(\mathrm{RD}=-9 \%, 95 \% \mathrm{Cl}-20$ to $3, \mathrm{p}=0.14)$, and $28.57 \%$ vs $22.64 \%$ $(\mathrm{RD}=-6 \%, 95 \% \mathrm{Cl}-18$ to $6, \mathrm{p}=0.34$ ). DAS28 remission at 2 years was $36.84 \%$ in standard vs $30.93 \%$ in intensive $(R D=-6 \%, 95 \% \mathrm{Cl}-17$ to $5, p=0.28)$. No superiority of the intensive group was seen in ACR20-50-70 response rates at 4 , $8,12,24$ months. The overall frequency of adverse events (AE) in patients that completed the trial was comparable between groups. The percentage of patients who discontinued for $\mathrm{AE}$ was higher in the intensive group $(9.32 \%$ in standard vs $16.52 \%$ in intensive, $\mathrm{RD}=7 \%, 95 \% \mathrm{Cl} 1$ to $13, \mathrm{p}=0.01$ ).

Percentage of patients who achieve remission at 12 months

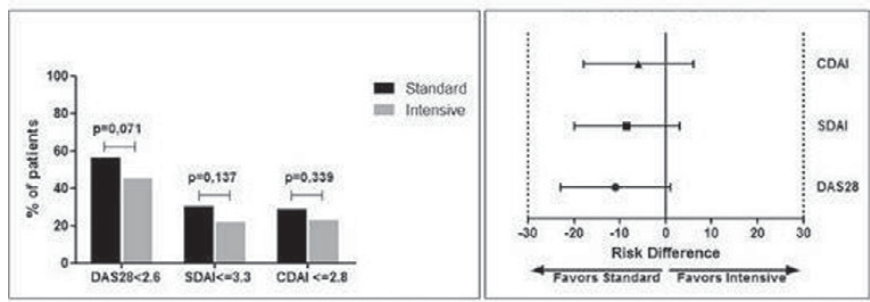

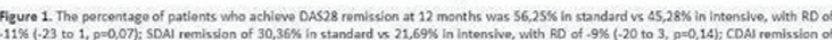
28,575 in standard $v 3222.645$ in intensive, with $R D$ of $-6 \%(-18$ to $6, p=0,34)$.

Conclusions: Our results confirm that intensive treatment with biologics in early, aggressive RA might be considered to induce and maintain clinical remission. The addition of high-dose GC to a first line treatment with ADA and MTX did not prove to induce a further improvement in efficacy. Although these results should be tested with other biologic therapies, the high rate of drop out for $A E$ in the intensive group should be carefully considered in the risk-benefit ratio.

Disclosure of Interest: None declared

DOI: 10.1136/annrheumdis-2017-eular.2362 